\title{
Assessing the Implications of Deviant Behavior on Society in Central Punjab Pakistan
}

\author{
${ }^{1}$ Muhammad Arqam Mushtaq, ${ }^{1}$ Muhammad Idrees*, ${ }^{2}$ Muhammad Roman \\ ${ }^{1}$ Department of Sociology GC University Faisalabad, Pakistan \\ 2 University of Agriculture Faisalabad, Pakistan \\ *muhammadidreesmalik@yahoo.com,rizvi356@gmail.com
}

\begin{abstract}
The present study has been designed to assess Implication of deviant behavior among in Central Punjab Pakistan. Generally, crime is treated as the unexpected behavior of an individual which goes against the law. The main purpose of this study is to analyze the implications of crime in society. In Pakistan, lower socio-economic status holders are involved in crimes as well as high socio-economic holders are also involved, hence they want to accumulate more wealth through illegal ways. Crime affects the state in social, economic and psychological terms. The present study was conducted in central Punjab. A sample of 300 respondents was selected by using convenient sampling technique from the one selected district of the central Punjab. Moreover, data was with the help of a well-designed interview schedule. Collected data was analyzed by using SPSS. On the bases on finding it was concluded that there are number of socio-economic and psychological factors that created problems in state and become hurdle in the sustainable development of Pakistan and this problem badly damage the whole sphere of the society. Some policy measure and recommendations was also proposed by the study to cope with this problem.
\end{abstract}

Keywords: Crime, Deviant Behavior, Implication, Chi-Square, Regression

\section{Introduction}

Crimes have always plagued every society in human history. The history of crime is as old as history of mankind. The first crime was committed by Cain, the first son of Adam and Eve, when he murdered his brother Abel out of jealousy. Crime is a major source of insecurity and discomfort in every society. There is no doubt that crime inflicts enormous monetary and psychological costs on society. The act of criminality gives rise to the feeling of insecurity and fear to those who have not been a victim as well. This sense of panic of being victimized generates negative effects on well-being. Crime can be defined as a wrongdoing classified by the state or the parliament of the country or law of the land. Each country sets out series of acts (crime), which are prohibited, and punishes a criminal of these acts by a fine or imprisonment or both. There is no universal and permanent definition of crime. It differs in different times in different regions. In Asian countries like Pakistan more than half of the population have income under the national Poverty line, and most of the population especially youth is unemployed (Altindag, 2012). Crimes in Pakistan have reached to an extraordinary and terrifying level, so insecurity among 180 million citizens has reached at peak. At a glance, Pakistan's biggest cities, commercial and industrial hub like Lahore, Islamabad, Quetta, and Peshawar is enough to shiver down the backbone of every citizen. It is heard a lot about the official claim that unemployment is going down but regrettably, unemployment is going high due to crime rate is also high. However, most citizen of Pakistan hits in the lesser civilized areas, due to which they suffer from extreme depths of unemployment and poverty, which is somewhat the main reason to commit the crime among the youth (Birks, Townsley, \& Stewart, 2012). The other major factors like lawlessness, fundamentalism, backwardness, double standards prevailing in the society and political instability are also responsible for high crime rate (Edmark, 2005). In and out migration in Pakistan has also an impact on crime as the circumstances shows that, those people who migrate to Pakistan, they don't have any systematic record and have also a political influence so that they got involve easily in crime. In Pakistan, lower socio-economic status holders are involved in crimes as well as high socio-economic holders are also involved, hence they want to accumulate more wealth through illegal ways. Literature shows that mostly criminals commit crime on the behalf of political parties, law enforcement departments and legal system of Pakistan. The statistics of crime of Pakistan shows that, Pakistan is not performing well in social, economic, cultural and technological environment (Anderson, 2004).

Impact of Crime: Crime generates substantial costs to society at individual, community, and national levels. The financial costs of certain impacts of crime are readily recorded, such as the value of stolen property and the amount of money spent on crime prevention and enforcement. These are referred to as the "economic 
costs". Other impacts are not fully or directly reflected in the financial consequences of crime, such as trauma, physical injury and change of lifestyle as a result of fear of crime. "Social costs" refers to these impacts that cannot be readily expressed in cash terms. For a comprehensive assessment, both of the costs must be taken into consideration. It would be misleading and incomplete to measure only the economic costs as this would omit important impacts of crime and so would tell only part of the story. Crimes such as robbery or rape, which have significant 'intangible' costs, would appear much less serious than they actually are, whilst other crimes would appear relatively more serious. It is therefore important to try and quantify all the impacts of crime in common terms as far as possible. Money can be used in this situation simply as a means of comparing one thing (e.g. the physical impact of a broken leg) with another (e.g. the cost of a hospital bed). However, in this paper, no attempt is made to classify each cost as either economic or social due to practical difficulties. Economic and social costs are treated as one and the same (Cohen, 2015).

Costs of crime are numerous, some of which are difficult or even impossible to quantify due to either practical difficulties or non-availability of relevant data. Even though researchers try as far as possible to compute all consequences of crime in cash terms, no study has ever fully assessed the myriad costs of crime. Brand and Price (2000) , for example, categorized costs of crime into 'cost in anticipation of crime', 'cost as a consequence of crime' and 'cost in response to crime'; and listed the types of costs that were included in their study as well as those that could not be estimated for theoretical reasons or lack of data. The relevant costs are as follows:

$>$ Cost in anticipation of crime: These fall mainly on people as potential victims - for instance, what they pay for security measures.

$>$ Estimated - security expenditure and insurance resources.

$>$ Not estimated - precautionary behavior, fear of crime/quality of life of potential victims, collective/community defensive expenditure, government crime prevention activities, and insurance premium. The above methodology of Mayhew and estimates the various costs mentioned.

> Medical costs: Medical costs relates to the costs of treatment in and outside hospital for victims who sustained physical injury. They are applied to homicide cases as well. Mental health costs are not included. Mayhew derived medical costs from estimates taken from a thorough study by the Monash University Accident Research Centre (MUARC) of the costs of deaths and injuries in Victoria in 1993-94, one cause of which is interpersonal violence. MUARC included medical costs for fatalities, hospitalization and non-hospitalization cases (Kerezsi \& Lévay, 2008).

$>$ Lost output: Lost output counts the costs of victims not being able to work. It is what in economic terminology is called human capital loss - commonly used in Australia to cost accidents and disease. Both paid and unpaid work is usually accounted for - that is, the lost production that a dead or injured victim would have contributed, but in present value. Unpaid work losses come from the imputed worth of household services and voluntary community work. The value of potential lifetime work is translated back to the year in which a death or injury occurred using a "social discount rate.

$>$ Intangible costs of crime (such as fear, pain, suffering and lost quality of life) do not reflect any resource use, but are now usually included as a legitimate cost to estimate. Nonetheless, estimates of intangible costs are the most tenuous. Three main approaches to estimate them have been taken in UK and US studies as follows: Estimation in terms of the amount of money individuals are willing to pay to reduce risks (either of dying or avoiding harm), e.g. by investing in safety gadgets or shifting to a 'safer' neighbourhood, ii. Measuring intangible losses through jury or court awards for noneconomic compensation to victims (or their survivors). iii. British Crime Survey approach, in which victims were asked to say what their desired compensation would be to account for the physical and emotional impact of what had happened (Kerezsi \& Lévay, 2008).

$>$ Criminal justice system costs A substantial amount of money is borne by the government in criminal justice system, which comprises the police, the judiciary, public prosecutor, prisons etc. Public records or media reports of expenditures of or government allocations to these departments are taken at "face value" to evaluate the costs of criminal justice system (Kerezsi \& Lévay, 2008).

The physical and emotional impact of crime can be devastating both for those who are harmed and for their families and friends. No matter what the crime or circumstances in which it was committed, it may diminish the victims' sense of control and self-worth. Crime however, affects different people in different ways. The 
way you feel will also vary over time and may even differ from day to day. A common initial reaction is feeling numb, and not believing what has happened to you. You may feel helpless and that no-one understands what you are going through. You may feel shocked, fearful or angry. It may help you to know that what you are feeling and experiencing are normal reactions to an abnormal and distressing event. Depending on your situation, you may experience a combination of reactions, feelings and symptoms. Peoples feels Cognitive difficulties like:

- Disorientation

- Confusion

- difficulty problem solving

- memory problems

- poor attention spans

- disturbed thinking

- blaming someone

- reliving the event

- distressing dreams

- People portray different Emotional responses towards crime:

- fear/anxiety

- anger

- depression

- grief

- guilt

- feeling helpless

- feeling isolated

- desire to withdraw/hide

In most cases these reactions, feelings and symptoms are temporary. Many people recover within a few weeks or months. For some however, the reactions, feelings and symptoms persist. It is important to look after yourself, and to get any support and treatment you need. Family members and friends may provide you with the support you need. Those not directly affected by crime often can't understand how difficult the recovery can be. At times they may not be able to provide you with the help or support you need when you need it. They may be dealing with their own reactions to the crime or other issues in their lives (Detotto \& Otranto, 2010). According to Tita, Petras, and Greenbaum (2006) "crime serves as an important catalyst for change in the socio-economic composition of communities. The effect crime has on the local property value is one of those catalyst effects. The question whether crime rates affect housing prices has been a popular subject of research over the last decades. However, although most empirical studies confirm that there is a negative impact of crime on housing prices, there is still no real consensus on the extent of this impact. The availability and quality of crime statistics (e.g., how should one incorporate non-recorded crime?), dealing with changes over time, the displacement effect, and the fact that the housing prices are determined by a complex set of factors and not just crime, are the most important reasons of this lack of consensus.

Another effect of crime is that residents become less committed to their communities, causing the 'social fibre' of the community to be weakened. An example of the loss of social capital is that residents of neighbourhoods with a criminal reputation are judged to be associated with criminal activities, leading (amongst others) to stigmas that, for example, prevent those people from finding jobs (Detotto \& Otranto, 2010).

Further examples of secondary economic effects of crime:

- The carbon cost of crime.

- The opportunity costs of police, rescue, and fire departments.

- Moving costs of residents who want to escape from crime levels in "bad" neighborhoods (Detotto and Otranto, 2010).

Gravity of the Problem: In every society, there are many social problems which are universal, crime is one of them. Crime is social problems, which affect and influence all societies. There is no society in any part of the world, which is without crime. Crime is looked upon primarily as a social problem, although there are certain 
many other aspects. Crime cause public concern; they occupy a priority position among social problem; they challenge the ability of modern society's institutions and recourses to control. Public concern priority potion challenge to social control and value orientation are among the chief component of social problems. Practically all societies look upon crime as a social phenomenon, no matter how infrequently it occurs. It usually some injury or harm to other. It looked upon as assort of threat to society's ability to contain. It violates sacred customs laws and values. It interrupts the smooth operation of the social and political order. However, crime and delinquency usually have a very low priority, if you are rating the major problems of united states. Problems such as security, food, economic development, migration, health, population, infrastructure, education, generate a much greater sense of urgency and importance (Rumbaut \& Ewing, 2007). Pakistan is no exception as compared with the other societies of the world and is also facing the problem of crime, which ranges from petty theft to robbery, raping, burglary, and murder. There are, however, certain crimes, which are condemned by the people of all races and colors. Such crimes are universally and equally viewed as serious delinquency and deviancy. Murder is one of such crimes. Crimes are fast increasing in rate and frequency in this part of the world. The gravity of the situation is so alarming that it has disturbed the social fabric of the society by means of its severe psychological and emotional impact. Heinous murders are being reported and the perpetrators are close acquaintances (Jaffer, 2003).

Present study has been designed to explore the factors promoting criminal behavior among youth and its implications in Punjab, Pakistan. Pakistan is the $6^{\text {th }}$ largest country of world that has more youthful population. The large youth cohorts are very useful for the development of any country but unfortunately these youth cohorts are involved in criminal activities due to the lack of counseling and job opportunities. In Pakistan, Socio-economic and psychological risk factors are higher as compared to the development opportunities. There are geographical areas where youth easily find opportunity to commit crime. All these factors promote the crime rate in the world as well as in Pakistan. Pakistani Society facing high level of crimes due the higher intensity of social, economic, environmental and psychological risk factors that pushes youth towards the crime. In Pakistan, lower socio-economic status holders are involved in crimes as well as high socio-economic holders are also involved, hence they want to accumulate more wealth through illegal ways. Literature shows that mostly criminals commit crime on bases of socio-economic inequalities. The statistics of crime in Pakistan shows that, Pakistan is not performing well in social, economic, cultural and technological environment. Moreover, the problem of crime badly affects the whole fabric of the Pakistani Society. It harms the victim as well as the families of the victims in emotional, physical social and economic ways. Criminal activities also effect badly to the overall economic and social segment of the country.

\section{Objectives of the Study:}

- To investigate implications of deviant behaviour on society

- To explore the ways for preventing youth's offending/involvement in criminal behaviour

\section{Literature Review}

Social disorganization theory: focuses on the urban conditions that effect crime rates. A disorganized area is one in which institutions of social control, such as family, commercial establishments and schools have broken down and can no longer perform their expected or stated functions. Indicators of social disorganization include high unemployment and school dropout rates, deteriorated housing, low income levels and large numbers of single parent households. Residents in these areas experience conflict and despair, and as a result, antisocial behavior flourishes (Wolff, Blitz, Shi, Siegel, \& Bachman, 2007).

Cultural deviance theory: combines elements of both strain and social disorganization theories. Because of this view...a unique lower-class culture develops in disorganized neighborhoods. Criminal behavior is an expression of conformity to lower class sub-culture values and traditions, not a rebellion against traditional society (Rock, 2007).

Rational choice: Classical criminology stresses that causes of crime lie within the individual offender, rather than in their external environment. For classicists, offenders are motivated by rational self-interest, and the importance of free will and personal responsibility is emphasized. Rational is the clearest example of youth bulge (Eadie, Morley, Baldock, Manning, \& Vickerstaff, 2003). 


\section{Methodology}

The methodological techniques and ways of analyzing the observations play a significant role in social research. Social scientists have commonly been using comprehensive sociological approach and advance techniques in social research in the modern era. Social scientists now use the sophisticated methodological tools and techniques in social research. The present study was conducted in the Punjab Pakistan. Multistage sampling technique was used to draw the sample. A first stage two districts of Central Punjab Lahore and Faisalabad was selected. At second stage one town from each selected city was selected. At third stage two union councils of each town was chooses. A sample of 300 respondents was drawn conveniently from the selected Union Councils. Moreover, data was collected with the help of a well-structured interview schedule. The collected Data was analyzed with the help of Statistical Package for Social Sciences (SPSS) Version-20. The data was presented in the form of bivariate and multivariate analysis.

\section{Results and Discussion}

It is important part of the study that provides the empirical findings from the experiments. Results are given below:

Bivariate Analysis: It explains the interaction between explanatory and response variables. The strength of relationship is checked by the chi-square and gamma statistics. This relationship might be significant or nonsignificant. Bi-variate analyses showing the relationship between two variables were described as under:

Research Hypothesis 1: Prevailing inequalities in society is responsible for deviance among youth that damage the social setup of the state

For chi-square test statistic hypothesis assumed as under:

$\mathrm{H}_{0}$ : There is no association between prevailing Inequalities and effect on the social setup

$\mathrm{H}_{1}$ : There is an association between prevailing Inequalities and its effect on the social setup

Table 1: Association between existing inequalities in society and their effects on the state

\begin{tabular}{|c|c|c|c|c|c|}
\hline \multicolumn{5}{|c|}{ Inequalities in the society are Social effect on state } & \multirow{2}{*}{ Total } \\
\hline & & Lawlessness & Militancy & Violence/unrest & \\
\hline \multirow{2}{*}{ To Great extent } & Count & 4 & 36 & 97 & 137 \\
\hline & $\%$ of Total & $1.3 \%$ & $12.0 \%$ & $32.3 \%$ & $45.7 \%$ \\
\hline \multirow{2}{*}{ To Some extent } & Count & 56 & 39 & 10 & 105 \\
\hline & $\%$ of Total & $18.7 \%$ & $13.0 \%$ & $3.3 \%$ & $35.0 \%$ \\
\hline \multirow{2}{*}{ Not at all } & Count & 42 & 7 & 9 & 58 \\
\hline & $\%$ of Total & $14.0 \%$ & $2.3 \%$ & $3.0 \%$ & $19.3 \%$ \\
\hline \multirow{2}{*}{ Total } & Count & 102 & 82 & 116 & 300 \\
\hline & $\%$ of Total & $34.0 \%$ & $27.3 \%$ & $38.7 \%$ & $100.0 \%$ \\
\hline Test & Value & D.F. & \multicolumn{3}{|c|}{ P (Value) Significance } \\
\hline Pearson Chi-Square & 152.028 & 4 & \multicolumn{2}{|c|}{$0.000^{* *}$} & \\
\hline Gamma & -0.799 & -- & \multicolumn{2}{|c|}{$0.000^{* *}$} & \\
\hline
\end{tabular}

Table 1 describes the independence between the inequalities in society and their effects on state. The value of chi-square and Gamma shows the highly significant association between the two variables. Therefore, the null hypothesis that, "There is no association between prevailing Inequalities and effects on state" is rejected and alternative hypothesis accepted. There strong association between explanatory and response variables. The research results coincide with Moser and Rodgers (2005) argue that there is a link between violence and unequal access to employment, education, health and basic physical infrastructure. They argue that situations of widespread, severe inequality heighten the potential for alienated, frustrated and excluded populations 
(particularly younger men) to engage in different forms of violence, including economic-related gang violence, politically motivated identity conflict and domestic violence. Likewise, research results match with Frances (2008) argues that horizontal inequalities (defined as inequalities in economic, social or political dimensions or cultural status between culturally defined groups) are an important cause of violent conflict. There is an increased probability of conflict occurring where socio-economic horizontal inequalities are high, especially when these are consistent with political inequalities.

Research Hypothesis 2: deviant behavior among Youth creates problems for state like uncertainty, extremism, and fear

For chi-square test statistic hypothesis assumed as under:

$\mathrm{H}_{0}$ : Attributes deviant behavior and types of state problems are independent/no association

$\mathrm{H}_{1}$ : Attributes deviant behavior and types of state problems are associated

Table 2: Association between deviant behavior and types of problems being faced by a state

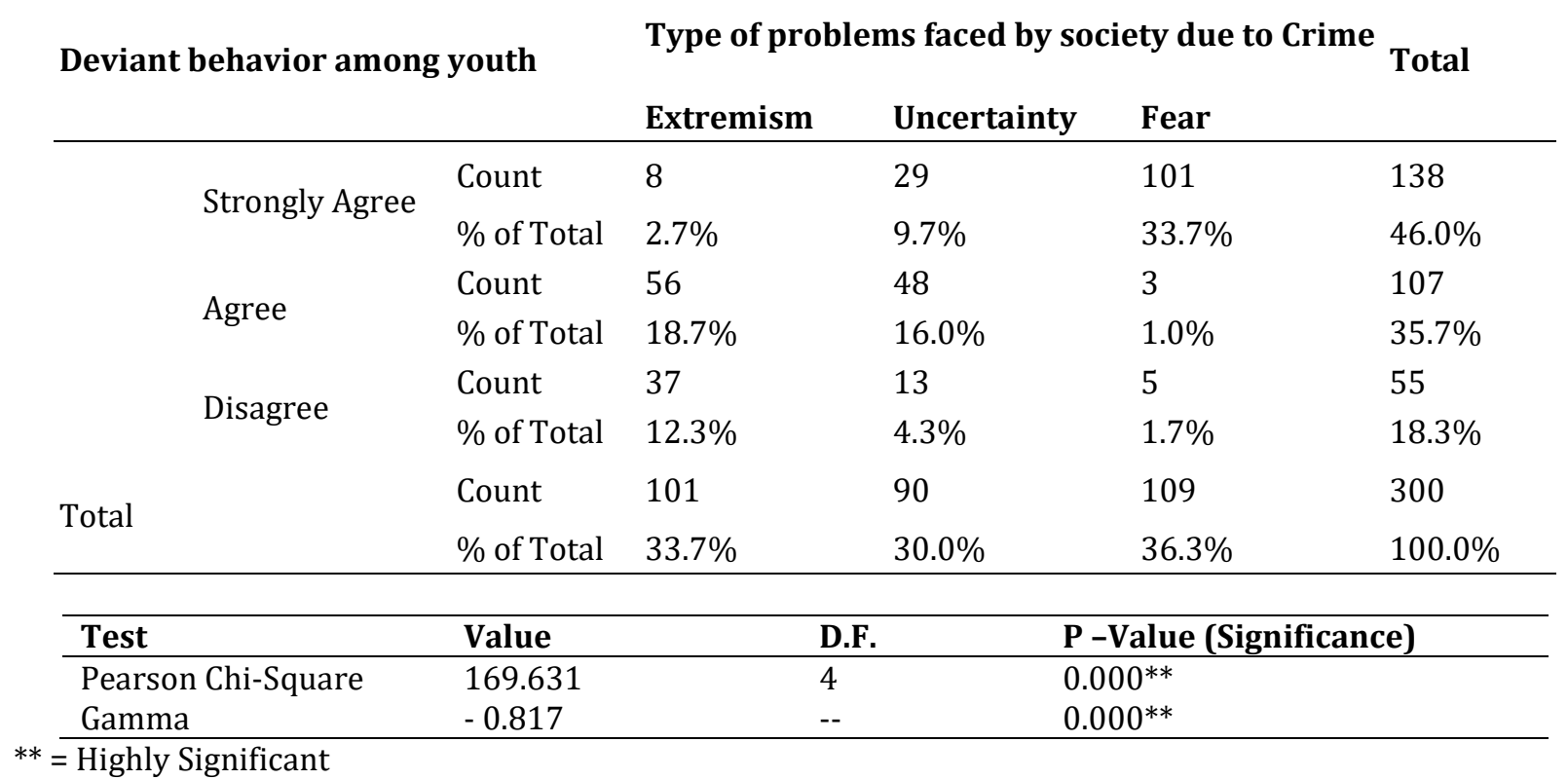

Table 2 explains the independence between youth deviance and problem a state faced due to offence among youth. The value of chi-square and Gamma shows the highly significant association between the two variables. Therefore, the null hypothesis that, "Attributes deviant behavior and types of state problems are independent/no association" is rejected and alternative hypothesis accepted. The value of Gamma shows the strong negative relationship between variables. Results were coincide with Urdal and Hoelscher (2012) concludes that countries with large youth cohorts do have higher rates of conflict than countries with smaller cohorts but he contends that there is no clear threshold as to how many young men make countries more prone to conflict. Furthermore, he adds that youth bulges are more likely to cause armed conflict when combined with economic stresses. Likewise, Same results were also found by Khan et al. (2011) that Youth increase the crime in the state, juvenile delinquency is a reason of youth bulge. The youth delinquent behavior spans from mugging, mobile snatching to murder. Likewise, Unnever, Benson, and Cullen (2008) found that there is an association between high proportions of youth in the population and a rise in political violence, civil unrest, state repression and state militancy. Indeed, countries with a large proportion of young adults in the population are much less likely to attain a stable liberal democracy than countries with a more mature age structure. 
Table 3: Influence of various explanatory variables on response variable: A multiple linear regression analysis

\begin{tabular}{|c|c|c|c|c|c|}
\hline Independent variable & \multicolumn{2}{|c|}{$\begin{array}{l}\text { Un-standardized } \\
\text { Coefficients }\end{array}$} & $\begin{array}{l}\text { Standardized } \\
\text { Coefficients } \\
\beta_{\mathbf{i}} \\
\end{array}$ & $\mathbf{t}_{\text {cal. }}$ & $\begin{array}{l}\text { Significance } \\
\text { (P-Value) }\end{array}$ \\
\hline (Constant) & 0.841 & 0.408 & & 2.061 & $0.040^{*}$ \\
\hline $\begin{array}{l}\text { Low Income Generation } \\
\text { Opportunities }\left(\mathrm{X}_{1}\right)\end{array}$ & 0.296 & 0.068 & 0.230 & 4.341 & $0.000^{* *}$ \\
\hline Economic Recession $\left(\mathrm{X}_{2}\right)$ & 0.280 & 0.054 & 0.263 & 5.176 & $0.000^{* *}$ \\
\hline Poverty $\left(\mathrm{X}_{3}\right)$ & 0.236 & .051 & 0.213 & 4.629 & $0.000^{* *}$ \\
\hline $\begin{array}{l}\text { Inequalities in the Society } \\
\left(\mathrm{X}_{4}\right)\end{array}$ & 0.136 & 0.047 & 0.127 & 2.891 & $0.004^{* *}$ \\
\hline $\begin{array}{l}\text { Adjusted } \mathbf{R}^{2}=\mathbf{0 . 6 3 5} \\
* *=\text { Highly Significant, } *=\text { Sigr } \\
\text { Response Variable: Implicati }\end{array}$ & $\begin{array}{l}\text { F } \\
\text { ificant } \\
\text { ons of D }\end{array}$ & $\begin{array}{l}\text { 2. } 648 \text { P-Val } \\
\text { t Behaviour }\end{array}$ & $\begin{array}{l}\text { e (Significance } \\
\text { Society }\end{array}$ & $0.000^{* *}$ & \\
\hline
\end{tabular}

Multivariate Analysis: Bivariate analysis is commonly used to assess the co-variation and the direction of relationship between two variables. However, in most of the cases these relationships do not provide sufficient ground for the casualty of relationship. Therefore, in order to develop causal relationship, some other variables were inserted into the investigation. In present study, in order to observe the influence of explanatory variables on dependent variable multiple regressions procedure was carried out, which is one of the suitable techniques for developing causal relationship between independent variables (explanatory variables) and dependent variable. The overall model look depicts that all contributory factors (regressors) had a highly significant impact on the dependent variable (regressond). The value of coefficient of determination depicts that independent variable has 63.5 percent change in the dependent variable i.e. a high degree of relationship between variables. The value of ANOVA also shows less dispassion and significant relationship.

The variable wise description of regression model is given below:

The highly significant P-value $=0.000$ for the regression coefficient bi=0.296, for the variable "low income generation opportunities" that increase the risk of youth crime and violent conflict had at least 0.296 points. The result shows that there is a highly significant association between the low income generation opportunities and violent conflict in the state. Research finding was acknowledge with Collier (2000) found that the willingness of young men to join a rebellion depends on their other income-earning opportunities. If young people are left with no alternative but unemployment and poverty, they are likely to join a rebellion as an alternative way of generating an income. For a rebel force to initiate a rebellion and increase violent conflict and the rebel force must grow rapidly, and that the likelihood it will succeed is much smaller if there is a relatively tight labor market.

The highly significant $p$-value $=0.000$ with regression coefficient $b i=0.280$ for the variable "Economic recession" shows a strong relationship that increase the youth deviance 0.280 . The inference describes that economic recession and youth bulge/unrest had highly significant association. Research results were acknowledged with Marcus and Gavrilovic (2010) concluded that the effects of the global economic crisis have been uneven, very few countries have been unscathed by the immediate and knock-on effects of declining demand for exports, reduced remittances, reduced opportunities for migrants and declining aid budgets. The effects of these on employment, public sector revenues and services have been compounded by sharp rises in food and fuel prices, impacting severely on poor people and pushing many millions more into poverty. The cumulative effects of these price rises, and of the often asset-depleting coping strategies that poor people have been forced to engage in, continue to make everyday survival difficult even in countries recovering from the economic crisis. Likewise, results also acknowledge with Ortiz and Cummins (2012) concluded that the global economic crisis hit many countries just as they were experiencing a youth bulge a 
demographic trend where the proportion of persons aged 15-24 in the population increases significantly compared to other age groups. The youth bulge has severe implications for labor markets worldwide. The jobs crisis is also severely threatening children and poor households worldwide through higher incidences of hunger and malnutrition, illness, child labor, lower educational outcomes, children being left alone and even abandoned, vulnerability to ongoing and future shocks, domestic violence and social unrest. The jobs crisis has further heightened the risk that workers, especially youth, are being permanently 'scarred' in terms of future employability and earnings potential.

The value of bi $=0.236$ with $p$-value $=0.000$ for the variable "Poverty" increased in poverty in the state caused 0.236-point increase in conflict and crime in the state like lawlessness, militancy. The drawn inference shows the highly significant association between the explanatory and explained variables. Results coincide with Pratt and Cullen (2005) find strong support for hypothesized associations between youth poverty, inequality and criminality across a variety of geographic units. However, there is general recognition that poverty and inequality have differential effects. Generally speaking, poverty is associated with higher levels of less violent crimes (such as property crimes) while inequality is more strongly associated with violent crimes, such as assault and homicide. The p-value 0.004 with regression coefficient $b i=0.136$ for the variable "inequalities in the state" caused increase 0.136 point in response variable. The inference shows that there is a strong relationship between both variables. The research results coincide with Moser and Rodgers (2005) argue that there is a link between violence and unequal access to employment, education, health and basic physical infrastructure. They argue that situations of widespread, severe inequality heighten the potential for alienated, frustrated and excluded populations (particularly younger men) to engage in different forms of violence, including economic-related gang violence, politically motivated identity conflict and domestic violence.

\section{Conclusion}

The results from study provide strong evidence in favor of a model of criminal behavior. There is no single factor that can be specified as the main cause of criminal behavior. This can more accurately be found in the way that multiple risk factors clustered together can interact in the lives of some children, while important protective factors are absent. Moreover, causes of crime differ from country to country, in western world; causes are directly related to the environment of the surroundings. These surroundings can be of school, home, neighborhood or playground. In contrast, causes of youth crime in Pakistan are significantly different from that of the western world. Here in Pakistan, the first main cause of youth crime is poverty, Unemployment, corruption in the law enforcing agencies, if corruption is eliminated; and state prove job opportunities to the youth than the major part of the problem will be solved. After identification of the root causes of crime in Pakistan, the remedial measures to control the criminal activities must revolve around those identified causes. These remedial measures include mainly the solution to the following problems, Corruption in law enforcing agencies, lack of authorities given to the agencies, unsolved issues of the agencies (like salary increment and provision of modern tools), technological backwardness in context of security tools, poverty and unemployment. Priority wise solution of the problems is the key to success. If the above mentioned remedial measures are taken into account, significant decrease in crime can be achieved.

\section{References}

Altindag, D. T. (2012). Crime and unemployment: Evidence from Europe. International Review of Law and Economics, 32(1), 145-157.

Anderson, C. A. (2004). An update on the effects of playing violent video games. Journal of adolescence, 27(1), 113-122.

Birks, D., Townsley, M. \& Stewart, A. (2012). Generative explanations of crime: using simulation to test criminological theory. Criminology, 50(1), 221-254.

Brand, S. \& Price, R. (2000). The economic and social costs of crime.

Cohen, E. (2015). Young elephants in Thai Tourism: A fatal attraction. Animals and tourism: Understanding diverse relationships, 163-177.

Detotto, C. \& Otranto, E. (2010). Does crime affect economic growth? Kyklos, 63(3), 330-345. 


\section{Journal of Social and Development Sciences (ISSN 2221-1152)}

Vol. 8, No. 4, pp. 33-41, December 2017

Eadie, T., Morley, R., Baldock, J., Manning, N. \& Vickerstaff, S. (2003). Crime, justice and punishment. Social policy.

Edmark, K. (2005). Unemployment and crime: Is there a connection? The Scandinavian journal of economics, $107(2), 353-373$.

Jaffer, J. (2003). Congressional control over treaty interpretation. The University of Chicago Law Review, 70(3), 1093-1117.

Kerezsi, K. \& Lévay, M. (2008). Criminology, crime and criminal justice in Hungary. European Journal of Criminology, 5(2), 239-260.

Khan, M. R., Behrend, L., Adimora, A. A., Weir, S. S., White, B. L. \& Wohl, D. A. (2011). Dissolution of primary intimate relationships during incarceration and implications for post-release HIV transmission. Journal of Urban Health, 88(2), 365-375.

Rock, P. (2007). Theoretical perspectives on victimisation. Handbook of victims and victimology, 37-61.

Rumbaut, R. G. \& Ewing, W. A. (2007). The myth of immigrant criminality and the paradox of assimilation: Incarceration rates among native and foreign-born men: Immigration Policy Center, American Immigration Law Foundation.

Tita, G. E., Petras, T. L. \& Greenbaum, R. T. (2006). Crime and residential choice: a neighborhood level analysis of the impact of crime on housing prices. Journal of quantitative criminology, 22(4), 299.

Unnever, J. D., Benson, M. L. \& Cullen, F. T. (2008). Public support for getting tough on corporate crime: Racial and political divides. Journal of Research in Crime and Delinquency, 45(2), 163-190.

Urdal, H. \& Hoelscher, K. (2012). Explaining urban social disorder and violence: An empirical study of event data from Asian and sub-Saharan African cities. International Interactions, 38(4), 512-528.

Wolff, N., Blitz, C. L., Shi, J., Siegel, J. \& Bachman, R. (2007). Physical violence inside prisons: Rates of victimization. Criminal justice and behavior, 34(5), 588-599. 